\title{
Effects of Ophthalmic Formulations Containing Cilostazol Nanoparticles on Retinal Vasoconstriction in Rats Injected with Endothelin-1
}

\author{
Nagai $\mathbf{N}^{1}$, Yoshioka $\mathbf{C}^{1}$, Tanabe $\mathbf{W}^{1}$, Tanino $\mathrm{T}^{1}$, Ito $\mathbf{Y}^{1 *}$, Okamoto $\mathbf{N}^{2}$ and Shimomura $\mathbf{Y}^{2}$ \\ ${ }^{1}$ Department of Pharmacy, Kinki University, 3-4-1 Kowakae, Higashi-Osaka, Osaka, Japan \\ ${ }^{2}$ Department of Ophthalmology, Kinki University Faculty of Medicine, Ohno-Higashi, Osaka-Sayama, Osaka, Japan
}

\begin{abstract}
Cilostazol (CLZ) is useful for the management of diabetic retinal vascular dysfunction and neuronal degeneration. However, drugdelivery in a posterior segment, such as retina,is not possible using eye drops with traditional formulations.In this study, we designed new ophthalmic formulations containing CLZ solid nanoparticles, and investigated whether these ophthalmic formulations provide noninvasive delivery systems targeting the posterior segment of the eye. The new ophthalmic formulations containing $1 \% C L Z$ solid nanoparticles were prepared byadding various additives $[0.005 \%$ benzalkonium chloride (BAC), $0.5 \%$ D-mannitol, 2 -hydroxypropyl- $\beta$-cyclodextrin (HP $\beta C D)$ and $1 \%$ methylcellulose] and subjecting the mixtures to mill methods $\left(C L Z_{\text {nano }}\right.$ ophthalmic formulations; particle size $61 \pm 43 \mathrm{~nm}$, mean \pm S.D.). The addition of HP $\beta C D$ and mannitol enhanced the stability of the CLZ dispersion $\left(C L Z_{\text {nano }}\right)$, and no precipitation from the $C L Z_{\text {nano }}$ ophthalmic formulations was observed until 21 days after preparation. In addition, in the measurement of the antimicrobial activity against Escherichia coli (ATCC 8739), the CLZ nanoparticles in ophthalmic formulations didn't affect the antimicrobial activityby preservative, such as BAC. In this study, retinal vasoconstriction was produced in rats by intravitreal injection of $1 \times 10^{-5} \mathrm{M}$ endotheline-1 $(15 \mu \mathrm{L}$, $\mathrm{ET}-1$ ); retinal vasoconstriction in ET-1-injected ratsreturned to normal by $48 \mathrm{~h}$ after injection. On the other hand, the instillation of $C L Z_{\text {nano }}$ ophthalmic formulations suppressed the retinal vasoconstriction in $\mathrm{ET}$-1-injected rats, and theretinal vascular caliber in rats instilled with CLZ was similar than that in non-treated rats $3 \mathrm{~h}$ after intravitreal injection. It is possible that dispersions containing CLZ nanoparticles provide new possibilities for an effective, noninvasive method to deliver therapeutic agents to intraocular tissues such as the retina, and that an ocular drug delivery system using drug nanoparticles may expand their usage as therapy in the ophthalmologic field.
\end{abstract}

Keywords: Nanoparticle; Cilostazol; Retina; Drug delivery system; Eye drop

\section{Introduction}

Most vision-threatening ocular diseases are associated with the intraocular structures, particularly the posterior segment-related diseases including age-related macular degeneration, diabetic macular edema and endophthalmitis. Recently, pharmaceutical approaches to these diseases have used steroids and oligonucleotides [1,2], and these drugs are generally administered via invasive methods, such as intravitreal injections and subtenon injections, because noninvasive methods to deliver these drugs are not available. However, repeated injections are associated with potential risks of complications, such as cataracts, vitreous hemorrhages and retinal detachment [3]. Moreover, patients may not comply with such regimens.Although, systemic administration has also been used to deliver therapeutic agents to the posterior segment of the eye, this route of administration requires large administration doses because of the inner and outer blood-retinal barriers that separate the retina and the vitreous humor from the systemic circulation [4]. Thus, there is a pressing need for noninvasive delivery systemstargeting the posterior segment of the eye.

In treating the posterior segments, it is very important to increase the effectiveness of ocular drugs by enhancing their bioavailability [5]. In order to overcome side-effects and increase ocular drug bioavailability, several strategies, including the preparation of viscous solutions, micro/nanoparticles and hydrogels, have been developed and investigated [6-12]. In the case of viscous solutions, numerous studies have demonstrated that they do not possess sufficient mechanical strength to resist the ocular clearance mechanism, and offer only a transient improvement in ocular residence time [13]. On the other hand, it has been reported that the capability of drugs to penetrate across the cornea can be significantly improved by decreasing the particle size using nanoparticles [8-10,14-16]. Ophthalmic formulations containing drug nanoparticles present a possible solution to the limitations surrounding ocular drug penetration [17-19], and it is known that decreasing direct cellular stimulation and reducing the amount of a drug used by increasing its bioavailability are useful ways to circumvent the side effects related to drug delivery [5]. It is expected that ophthalmic drug systems using nanoparticles may provide an alternative strategy for increasing ocular drug penetration [17-19]. Our previous reports showed that dispersions containing tranilast and indomethacin nanoparticles prepared by a bead mill methodcause less corneal damage to human corneal epithelium cellsandgreater corneal penetration than commercially available tranilast and indomethacin eye drops (RIZABEN ${ }^{\circ}$ eye drops, INDOMELOL ${ }^{\circ}$ ophthalmic solutions) [20-24]. It is possible that ophthalmic drug delivery systems using nanoparticles will provide a noninvasive way to target drugs to the posterior segment of the eye.

Cilostazol(6-[4-(1-cyclohexyl-1H-tetrazol-5-yl)butoxy]-

*Corresponding author: Ito Y, Faculty of Pharmacy, Kinki University, 3-4-1 Kowakae, Higashi-Osaka, Osaka, Japan, Tel: +816 43073640; Fax +8166730 1394; E-mail: itoyoshi@phar.kindai.ac.jp

Received February 26, 2015; Accepted March 14, 2015; Published March 21, 2015

Citation: Nagai N, Yoshioka C, Tanabe W, Tanino T, Ito Y, et al (2015) Effects of Ophthalmic Formulations Containing Cilostazol Nanoparticles on Retinal Vasoconstriction in RatsInjected with Endothelin-1. Pharm Anal Acta 6: 354 doi:10.4172/2153-2435.1000351

Copyright: ( 2015 Nagai N, et al. This is an open-access article distributed under the terms of the Creative Commons Attribution License, which permits unrestricted use, distribution, and reproduction in any medium, provided the original author and source are credited. 
Citation: Nagai N, Yoshioka C, Tanabe W, Tanino T, Ito Y, et al (2015) Effects of Ophthalmic Formulations Containing Cilostazol Nanoparticles on Retinal Vasoconstriction in RatsInjected with Endothelin-1. Pharm Anal Acta 6: 354. doi:10.4172/2153-2435.1000351

3,4-dihydrocarbostyril, CLZ) is well known to have anti-platelet aggregation and vasodilatory effects with minimal cardiac effects, and has been applied clinically to cerebrovascular diseases. Pharmacologically, CLZ has been found to increase intracellular cyclic Adenosine Monophosphate (AMP) levels by inhibiting its hydrolysis by type 3 phosphodiesterase, resulting in vasculoprotective effects $[25,26]$. In addition, it has been reported that CLZ treatment is useful for the management of diabetic retinal vascular dysfunction and neuronal degeneration [27], and intra-arterially administered CLZ induces vasodilation of the retinal arterioles of rats, which results in an increase in blood supply to the retina independent of changes in mean arterial pressure [28]. Therefore, if CLZcan be delivered to the retina by the instillation of an ophthalmic formulations containingCLZ, such formulation may beuseful for the therapeutic treatmentof the retina.

In this study, we designed new ophthalmic formulations containing CLZ solid nanoparticles using the bead mill method, and investigated whether these formulations provide noninvasive delivery systems targeting the posterior segment of the eye. In addition, we also demonstrate the preventive effect of ophthalmic formulations containing CLZ nanoparticles on retinal vasoconstriction.

\section{Methods}

\section{Animals and materials}

Male Wistar rats (72 rats), 7 weeks of agewere housed under standard conditions ( $12 \mathrm{~h} / \mathrm{d}$ fluorescent light (07:00-19:00), $25^{\circ} \mathrm{C}$ room temperature), and allowed free access to a commercial diet (CE-2, Clea Japan Inc., Tokyo, Japan) and water. All procedures were performed in accordance with the Kinki University Faculty of Pharmacy Committee Guidelines for the Care and Use of Laboratory Animals and the Association for Research in Vision and Ophthalmology resolution on the use of animals in research. CLZ microparticles (original CLZ)were kindly donated by Otsuka Pharmaceutical Co., Ltd. (Tokyo, Japan). 2-Hydroxypropyl- $\beta$-cyclodextrin (HP $\beta C D$, average molar substitution, 0.6; average MW, 1380)was purchased from Nihon Shokuhin Kako Co., Ltd. (Tokyo, Japan). Low-substituted methylcellulose (MC, METOLOSE SM-4, average viscosity, 4 Pa.s at $20^{\circ} \mathrm{C}$ ) was providedby Shin-Etsu Chemical Co., Ltd. (Tokyo, Japan). Benzalkonium chloride (BAC) was obtained fromKanto Chemical Co., Inc. (Tokyo, Japan). Mannitol (D-mannitol) was purchased from Wako Pure ChemicalIndustries, Ltd. (Osaka, Japan).All other chemicals used were of the highest purity commercially available.

\section{Preparation of ophthalmic dispersions containing CLZ nanoparticles}

CLZ nanoparticles were prepared using zirconiaballs, Puluerisette 7 (a planetary ball mill, Fritsch Japan Co.,Ltd, Tokyo, Japan) and Bead Smash 12 (a bead mill, Wakenyaku Co. Ltd, Kyoto, Japan). Zirconia balls (diameter: $10 \mathrm{~mm}$ ) were added to a zirconia cup (diameter: 45 $\mathrm{mm}$ ) containing CLZ microparticles (solid, original CLZ), BAC, mannitol or MC, and the mixture was crushed with the Puluerisette 7 for $24 \mathrm{~h}$ (400 rpm, room temperature). The mixture was dispersed in saline with or without $5 \% \mathrm{HP} \beta \mathrm{CD}$, and crushed with the Bead Smash $12\left(5,500 \mathrm{rpm}, 30 \mathrm{sec} \times 30\right.$ times, $\left.4^{\circ} \mathrm{C}\right)$ using zirconia beads (diameter: $0.1 \mathrm{~mm}$ ). The compositions of the dispersions containing CLZ are shown in Table 1. One percent CLZ is equivalent to 27.1mMCLZ; the $\mathrm{pH}$ was 6.5 for both ophthalmic dispersions containing CLZ microor nanoparticles. The particle sizes and imageswere obtained using a nanoparticle size analyzer SALD-7100 (Shimadzu Corp., Kyoto, Japan; refractive index 1.60-0.10i) and scanning probe microscope SPM-9700
(Shimadzu Corp., Kyoto, Japan), respectively. The image of dispersions containing CLZ nanoparticles $\left(\mathrm{CLZ}_{\text {nano }}\right)$ as described in Table 1 was created by combining a phase and height image using image analysis software connected to the SPM-9700. The solubility of CLZ in saline containing BAC, mannitol, MC and $5 \%$ HPßCD was $0.037 \%$ (the solubility of CLZin saline was $0.0005 \%$ ). In the penetration, the solvent containing additive was filtered through a Minisart CE (pore size of $0.20 \mu \mathrm{m}$, Costar, Cambridge, MA, USA), and was performed in aseptic technique.

\section{Stability of ophthalmic dispersions containing CLZ}

Three millilitersof ophthalmic dispersions containing CLZ as described in Table 1 were incubated in $5 \mathrm{ml}$ test tubesin the dark at $20^{\circ} \mathrm{C}$ for 7 day, after which $50 \mu \mathrm{l}$ of sample solution was withdrawn from $5 \mathrm{~mm}$ under the surface at the indicated time intervals (total height of liquid, $4 \mathrm{~cm}$ ). The CLZ concentrations in the samples were determined by the following HPLC method. Fifty microliters of filtrate was added to $100 \mu \mathrm{l}$ methanol containing $0.3 \mu \mathrm{g}$ benzophenone (internal standard), and the mixture was filtered through a Chromatodisk $4 \mathrm{~A}$ (pore size $0.45 \mu \mathrm{m}$, Kurabo Industries Ltd., Osaka, Japan). The solution $(10 \mu \mathrm{l})$ was injected into an Inertsil ${ }^{\circ}$ ODS-3 $(3 \mu \mathrm{m}$, column size: $2.1 \mathrm{~mm}$ $\times 50 \mathrm{~mm}$ ) column (GL Science Co., Inc., Tokyo, Japan) on a Shimadzu LC-20AT system equipped with a column oven CTO-20A (Shimadzu Corp., Kyoto, Japan). The mobile phase consisted of acetonitrile/ methanol/ water $(35 / 15 / 50, \mathrm{v} / \mathrm{v})$ at a flow rate of $0.25 \mathrm{ml} / \mathrm{min}$; the column temperature was $35^{\circ} \mathrm{C}$, and the wavelength for detection was $254 \mathrm{~nm}$. The retention times of CLZ was $3.7 \mathrm{~min}$, and internal standard used was benzophenone.

\section{Antimicrobial activity of dispersions containing CLZ nanoparticles}

$\mathrm{CLZ}_{\text {nano }}$ as described in Table 1 was tested for antimicrobial activity against $E$. coli (ATCC 8739). The organism was selected based on Japanese Pharmacopoeia (JP) test protocols [29]. According to the standard methodology, the bulk dilution was split into $10 \mathrm{~mL}$ aliquots, each ofwhich was inoculated with between $10^{5}$ and $10^{6}(\mathrm{CFU}) / \mathrm{mL}$ of E. coli(ATCC 8739) (1 organism per aliquot) and incubatedin the presence ofColony-Forming Units vehicle (solution containing $0.001 \%$ BAC, $0.5 \%$ mannitol, $5 \%$ HP $\beta C D$ and $0.5 \% \mathrm{MC}$ ) or CLZ-containing dispersions at $20^{\circ} \mathrm{C}$ to $25^{\circ} \mathrm{C}$. The inoculated samples were sampled and counted on days $2,7,14$ and 28 . One milliliter aliquots were serially diluted in phosphate buffer, plated induplicate on soybean-caseindigest agar (casein soya bean digest agar for JP general test, Wako, Osaka, Japan), and incubated at $31^{\circ} \mathrm{C}$ for 3 days. Raw data counts were converted to $\log (\mathrm{CFU})$ values. Since the samples were diluted at least $1: 10$ at the time of testing, $10 \mathrm{CFU}$ reduction is the lowest sensitivity allowed by the test.

\section{Assay of CLZ concentration in blood,cornea, lens, vitreous body, sclera, choroid,retina, anterior and posterior part}

Thirty microliters of dispersions containing CLZ micro- or nanoparticles $\left(\mathrm{CLZ}_{\text {micro }}\right.$ or $\left.\mathrm{CLZ}_{\text {nano }}\right)$ as described in Table 1was instilled into the right eye of rats, and the eyes were kept open for about $1 \mathrm{~min}$ to prevent the $\mathrm{CLZ}_{\text {micro }}$ or $\mathrm{CLZ}_{\text {nano }}$ from overflowing. After that, the rats were killed under deep isoflurane anesthesia, and the blood was collected fromthe vena cava10, 30 and 60 min after instillation of CLZ $(n=6)$. The cornea, lens, vitreous body,sclera, choroid, retina, anterior and posterior part as described in Fig. 1 were excised(the portion other than the retina is defined assclera and choroid because the tissueswere not further separable), homogenized in methanol on ice, and 
Citation: Nagai N, Yoshioka C, Tanabe W, Tanino T, Ito Y, et al (2015) Effects of Ophthalmic Formulations Containing Cilostazol Nanoparticles on Retinal Vasoconstriction in RatsInjected with Endothelin-1. Pharm Anal Acta 6: 354. doi:10.4172/2153-2435.1000351

Page 3 of 8

\begin{tabular}{|c|c|c|c|c|c|c|c|}
\hline \multirow{3}{*}{$\begin{array}{l}\text { Formulation } \\
\qquad \mathrm{CLZ} \text { micro }\end{array}$} & \multicolumn{5}{|c|}{ Content (w/v\%) } & \multirow{2}{*}{\multicolumn{2}{|c|}{ Treatment }} \\
\hline & \multirow{2}{*}{$\begin{array}{c}\begin{array}{c}\mathrm{CLZ} \\
\text { microparticles }\end{array} \\
1.0\end{array}$} & \multirow{2}{*}{$\begin{array}{l}\text { BAC } \\
0.001\end{array}$} & \multirow{2}{*}{$\begin{array}{c}\text { D-Mannitol } \\
0.1\end{array}$} & \multirow{2}{*}{$\begin{array}{c}\text { HP } \beta C D \\
5.0\end{array}$} & \multirow{2}{*}{$\begin{array}{l}\text { MC } \\
1.0\end{array}$} & & \\
\hline & & & & & & - & - \\
\hline Milled-CLZ $Z_{\mathrm{BAC}(-)}$ & 1.0 & - & 0.1 & 5.0 & 1.0 & Ball mill & Bead mill \\
\hline Milled-CLZ $Z_{\text {mannitol(-) }}$ & 1.0 & 0.001 & - & 5.0 & 1.0 & Ball mill & Bead mill \\
\hline Milled-CLZ $Z_{H P \subset C D(-)}$ & 1.0 & 0.001 & 0.1 & - & 1.0 & Ball mill & Bead mill \\
\hline Milled-CLZ ${ }_{\mathrm{MC}(-)}$ & 1.0 & 0.001 & 0.1 & 5.0 & - & Ball mill & Bead mill \\
\hline $\mathrm{CLZ}_{\text {nano }}$ & 1.0 & 0.001 & 0.1 & 5.0 & 1.0 & Ball mill & Bead mill \\
\hline
\end{tabular}

Table 1:Ophthalmic formulations of particle dispersionscontaining CLZ.

centrifuged at $10,000 \mathrm{rpm}$ for $15 \mathrm{~min}$ at $4^{\circ} \mathrm{C}$. CLZ in the supernatant was analyzed by the HPLC method described above. The area under the curve $\left(A U C_{\mathrm{CIZ}}\right)$ of the CLZconcentration versus time (minutes) (the area under the CLZ concentration-time curve), area underthe first moment curve $\left(A U M C_{\mathrm{CLZ}}\right)$ and mean residence time $\left(M R T_{\mathrm{CLZ}}\right)$ were calculated according to the following equations (Eqs. 1-3):

$$
\begin{aligned}
& A U C_{\mathrm{CLZ}}=\int_{0}^{60} C_{C L Z} d t \\
& A U M C_{\mathrm{CLZ}}=\int_{0}^{60} C_{C L \dot{Z}} t d t \\
& M R T_{\mathrm{CLZ}}=\frac{A U M C_{C L Z}}{A U C_{C L Z}}
\end{aligned}
$$

Where $t$ is the time after instillationof eye drops, $C_{\mathrm{CLZ}}$ is the CLZ concentration at time $t$. AUC was determined according to the trapezoidal rule up to the last CLZ concentration measurement point.

\section{Measurement of retinal vascular caliber}

Thirty microliters of CLZ $\mathrm{micro}_{\text {or }}$ oLZ $\mathrm{Cano}_{\text {na }}$ as described in Table 1 was instilled into the right eye of rabbits,and the eyes were kept open for about $1 \mathrm{~min}$ to prevent the CLZ ${ }_{\text {micro }}$ or CLZ $\mathrm{Cano}_{\text {nano }}$ from overflowing. After $5 \mathrm{~min}$, the eyes were dilated by the instillation of $0.1 \%$ pivalephrine (Santen Pharmaceutical Co., Osaka, Japan) under anesthesia (isoflurane), and $1 \times 10^{-5} \mathrm{M}$ endotheline-1 (15 $\mu \mathrm{L}$, ET-1) was injected (intravitreal injection). Changes in retinal vascular caliber (RVC) weremonitoredusing a Digital Microscope (Bio MedicalScience Inc., Tokyo, Japan) 0, 10, 30, 60, 120, 180 and $240 \mathrm{~min}$ after injection of ET-1 $(n=6)$; RVC was analyzed with image analyzing software Image J. Retinal vasoconstriction (\%)was calculated by the following Eq. 4:

Ratio of retinal vasoconstriction $(\%)=$

$$
\frac{\left(\mathrm{RVC}_{\text {without injection }}-\mathrm{RVC}_{\text {with injection }}\right)}{\mathrm{RVC}_{\text {without injection }}} \times 100
$$

$\triangle \mathrm{RVC}(\%)$ was analyzed as the difference in the ratio of retinal vasoconstriction in rats instilled with saline or eye drops (the enhancement of $\triangle \mathrm{RVC}$ shows a high protective effect against the retinal vasoconstriction). The area under the curve $\left(A U C_{\triangle \mathrm{RVC}}\right)$ of $\triangle \mathrm{RVC}$ versus time (minutes) (area under $\triangle \mathrm{RVC}$-time curve), area underthe first moment curve $\left(A U M C_{\triangle \mathrm{RVC}}\right)$ and mean residence time $\left(M R T_{\triangle \mathrm{RVC}}\right)$ were calculated according to the following equations (Eqs. 5-7):

$$
\begin{aligned}
& A U C_{D \mathrm{RVC}}=\int_{0}^{240} \Delta R V C d t \\
& A U M C_{D \mathrm{RVC}}=\int_{0}^{240} \Delta R V C \bullet t d t
\end{aligned}
$$

$$
M R T_{D \mathrm{RVC}}=\frac{A U M C_{\triangle R V C}}{A U C_{\triangle R V C}} \text { (7) }
$$

Where $t$ is a time after ET-1injection. AUC was determined according to the trapezoidal rule up to the last RVC value measurement point.

\section{Statistical analysis}

All values are presented as mean \pm Standard Deviation (S.D.) or Standard Error of the mean (S.E.). Unpaired Student'st-test was used to evaluate statistical differences, and multiple groups were evaluated by one-way analysis of variance followed by Dunnett's multiple comparison. $P$ values less than 0.05 were considered significant.

\section{Results}

\section{Establishment of ophthalmic dispersions containing CLZnanoparticles by bead mill methods}

Figure 2 and Table 2 show the particle size distributions (Figure 2) and mean particle diameters (Table 2) of dispersions containing $1 \%$ CLZ as described in Table 1. CLZ microparticles $(18.8 \pm 14.0 \mu \mathrm{m})$ containing BAC, mannitol, $\mathrm{HP} \beta \mathrm{CD}$ and $\mathrm{MC}$ were milled by the mill method to a meanparticle size of $61 \pm 43 \mathrm{~nm}$ (mean \pm S.D., CLZ Fig. 2E and G). On the other hand, CLZ reached a meringue state by the mill method using CLZ microparticles containing BAC, mannitol and $\mathrm{HP} \beta C D$ (Milled-CLZ ${ }_{\mathrm{MC}(-)}$, Fig. 2F). The CLZ particles obtained by the addition of BAC, mannitol and MC had a meanparticle size of 160 $\pm 101 \mathrm{~nm}$ (Milled-CLZ ${ }_{\mathrm{HP}} \beta_{\mathrm{CD}(-)}$, means \pm S.D.), and the meanparticle size of Milled-CLZ ${ }_{\mathrm{HP}} \beta_{\mathrm{CD}(-)}$ was larger than that of CLZ $Z_{\text {nano }}$. There was no difference in particle size among Milled-CLZ $Z_{B A C(-)}$, Milled-CLZ $Z_{\text {mannitol(-) }}$ and $C_{2 L}$. Figure 3 shows the stability of dispersions containing $1 \%$

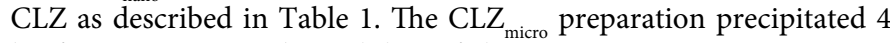
$\mathrm{h}$ after preparation. The stability of dispersions containing CLZ was increased by the combination of additive (BAC, mannitol or HP $\beta C D$ ) and the bead mill method. The addition of HP $\beta C D$ and mannitol enhanced the stability of the CLZ dispersion $\left(\mathrm{CLZ}_{\text {nano }}\right)$. The Milled-

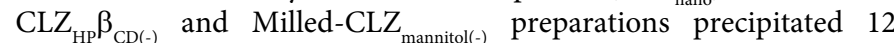
days and 18 days after preparation, respectively. On the other hand, no precipitation of the Milled-CLZ ${ }_{\mathrm{BAC}(-)}$ and $\mathrm{CLZ}_{\text {nano }}$ preparations was observed up to2 1 days after preparation. Although, the no antimicrobial activity of Milled-CLZ $Z_{\text {BAC(-) }}$ was observed, the CLZ $Z_{\text {nano }}$ preparation showed high antimicrobial activity approximately equal to that of the $0.001 \%$ BAC solution (Figure 4).

\section{Effect of ophthalmic dispersions containing CLZ nanoparticles on theretinaspfET-1-injected rats}

Figure 5 shows the CLZ concentrations in blood and cornea, lens, 
Citation: Nagai N, Yoshioka C, Tanabe W, Tanino T, Ito Y, et al (2015) Effects of Ophthalmic Formulations Containing Cilostazol Nanoparticles on Retinal Vasoconstriction in RatsInjected with Endothelin-1. Pharm Anal Acta 6: 354. doi:10.4172/2153-2435.1000351

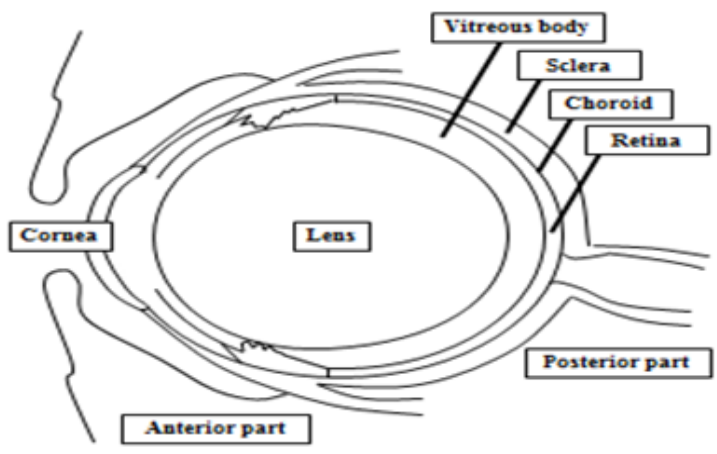

Figure 1: Locations sampled for the assay of CLZ concentration in the eyes of rats instilled with dispersions containing CLZ nanoparticles.
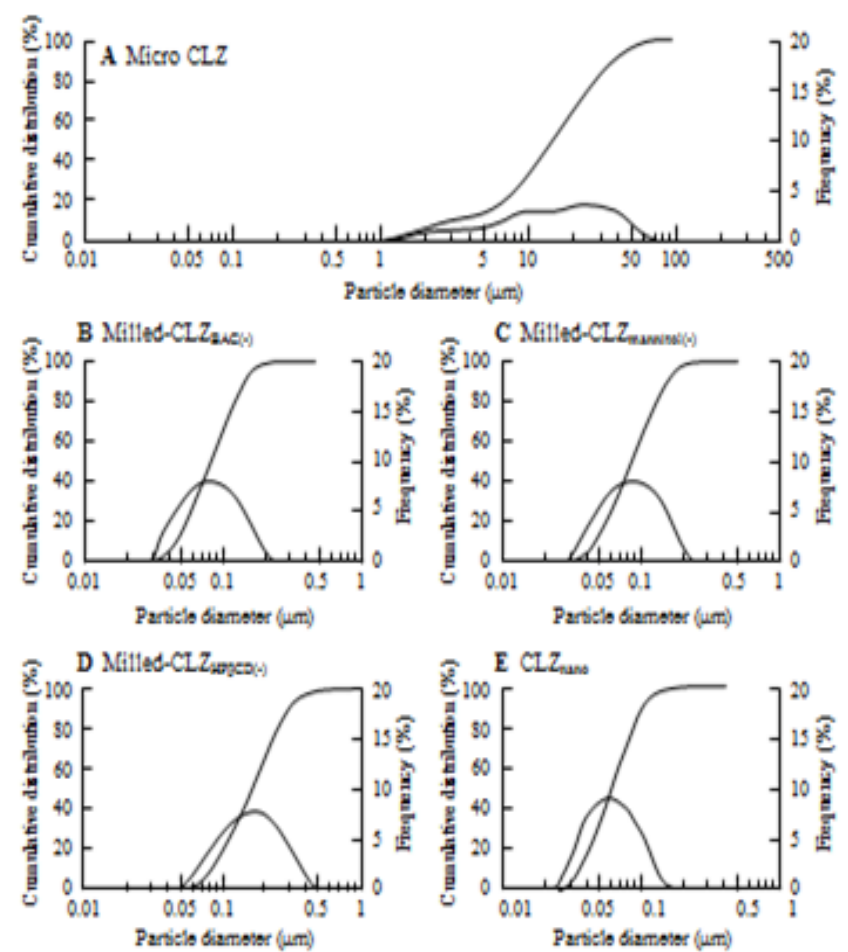

F Mailed-CLZ
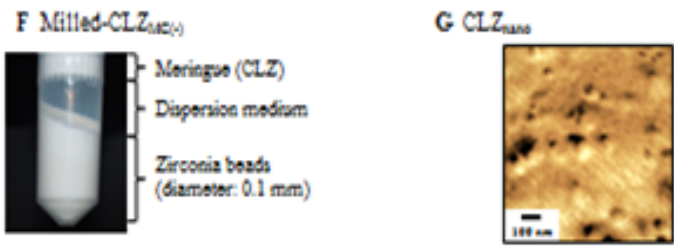

Figure 2: Cumulative size distribution, frequency and images of $1 \% \mathrm{CLZ}$ dispersions with or without BAC, mannitol, HPBCD and MC. A: cumulative size distribution and frequency of $C L Z$ microparticles, $B$ : cumulative size distribution and frequency of Milled-CLZ $Z_{\mathrm{BAC}(-)}, \mathrm{C}$ : cumulative size distribution and frequency of Milled-CLZ ${ }_{\text {mannito(-) }}$, D: cumulative size distribution and frequency of Milled$\mathrm{CLZ}_{\mathrm{HPBCD}(-)}, \mathrm{E}$ : cumulative size distribution and frequency of $\mathrm{CLZ}_{\text {nano }}, \mathrm{F}$ : image of Milled-CL $Z_{M C(-)}, G$ : image of $C L Z_{\text {nano }}$ by SPM- 9700 .

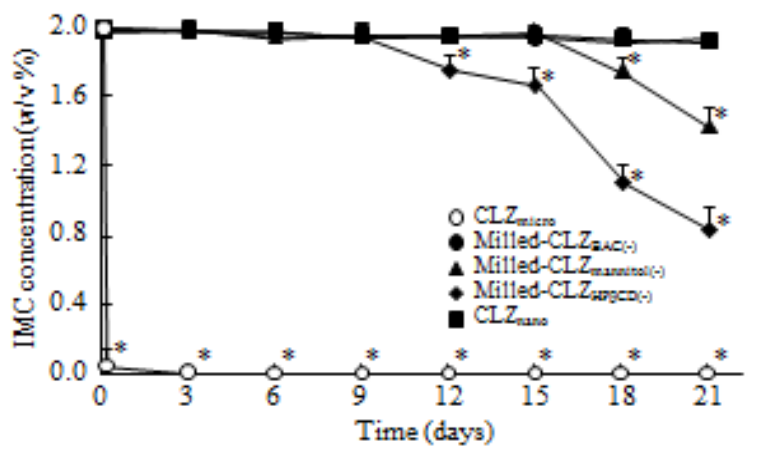

Figure 3: Stability of $1 \% \mathrm{CLZ}$ dispersions with or without BAC, mannitol, $\mathrm{HP} \beta C D$ and MC. $1 \% \mathrm{CLZ}$ dispersions were kept in the dark at $20^{\circ} \mathrm{C}$ for 21 days, and the amounts of remaining CLZ were determined at the indicated time points. The data are presented as means \pm S.E. of 6 independent sample.

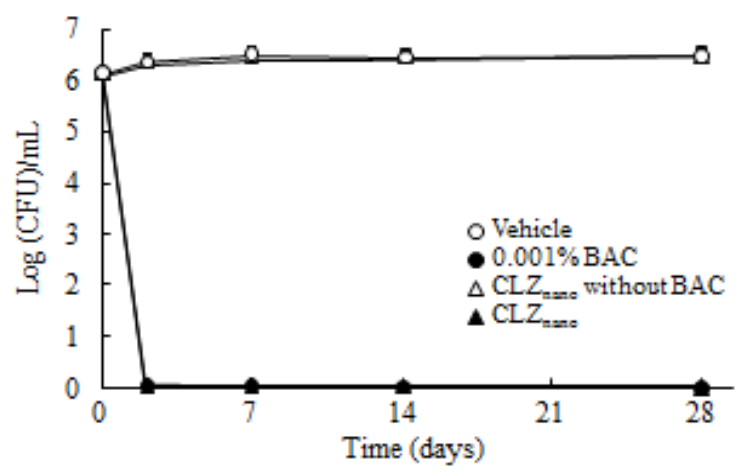

Figure 4: Evaluation of antimicrobial activities of dispersions with and without CLZ nanoparticles. Dispersions containing vehicle alone $(0.1 \%$ mannitol, $5.0 \%$ HPBCD, $0.5 \% \mathrm{MC}$ ), vehicle plus $0.001 \% \mathrm{BAC}$, vehicle plus $0.5 \% \mathrm{CLZ}$ nanoparticles (CLZ without BAC, Milled-CLZ vehicle plus $0.001 \%$ BAC and $1 \%$ CLZ nanoparticles $\left(C L Z_{\text {nano }}\right)$ were tested for antimicrobial activity against E. coli (ATCC 8739). Raw data counts were converted to $\log _{10}$ values, and are presented as means \pm S.E. of 6 independent experiments.

vitreous body, sclera, choroid, retina, anterior, posterior partof the right eyes of rats after eye drop instillation, and Table 3 summarizes the pharmacokinetic parameters calculated from the data in Fig. 5.No significant difference in plasma CLZ concentration was observed. On the other hand, in the right eye field, including the cornea, lens, vitreous body, sclera, choroid, retina, anterior and posterior part (Fig. 5B-H), the CLZ concentration in rats instilled with CLZ ${ }_{\text {nano }}$ were significantly higher than those in rats instilled with $\mathrm{CLZ}_{\text {micro }}$, and the $A U C_{\mathrm{CLZ}}$ values in the cornea, lens, vitreous body, sclera containing choroid, retina, anterior and posterior part were approximately 1.9, $1.8,8.0,6.2,8.2,24.1$ and 16.0-fold higher in rats instilled with CLZ than those instilled with $\mathrm{CLZ}_{\text {micro }}$. In contrast to the results in CLZ concentration in the right retina of rat instilled with $\mathrm{CLZ}_{\text {nan, }}$, the CLZ in the left retinas of rats, which did not receive instillations, was undetectable. Figure 6 shows the preventive effects of the instillation of $\mathrm{CLZ}_{\text {micro }}$ and CLZ $\mathrm{nano}_{\text {on }}$ retinal vasoconstriction in ET-1-injectedrats, and Table 4 summarizes the pharmacokinetic parameters calculated from the data in Fig. 6.Retinal vasoconstriction was induced by the 
Citation: Nagai N, Yoshioka C, Tanabe W, Tanino T, Ito Y, et al (2015) Effects of Ophthalmic Formulations Containing Cilostazol Nanoparticles on Retinal Vasoconstriction in RatsInjected with Endothelin-1. Pharm Anal Acta 6: 354. doi:10.4172/2153-2435.1000351

Page 5 of 8

\begin{tabular}{|c|c|c|c|c|}
\hline & CLZmicroparticles & Milled-CLZ & Milled-CLZ & Milled-CLZ \\
\hline $\begin{array}{c}\text { Particle size }\left(\times 10^{3}\right. \\
\mathrm{nm})\end{array}$ & $18.8 \pm 14.0$ & $0.079 \pm 0.055$ & $0.069 \pm 0.048$ & $0.160 \pm 0.101$ \\
\hline
\end{tabular}

TL particle size of CLZmicroparticles andin dispersions containing 1\% CLZas described in Table 1 were determined usinga nanoparticle size analyzer SALD-7100 (refractive index 1.60-0.10i). The data are presented as means \pm S.D.

Table 2: Changes in CLZparticle size in CLZdispersions with or without BAC, mannitol, HP $\beta C D$ and MC.

\begin{tabular}{|c|c|c|c|c|}
\hline & & $A \cup C_{\mathrm{CLZ}}(\mathrm{nmol} \cdot \mathrm{min} / \mathrm{g}$ or $\mathrm{ml})$ & $A U M C_{\mathrm{CLZ}}\left(\mathrm{nmol} \cdot \mathrm{min}^{2} / \mathrm{g}\right.$ or $\left.\mathrm{ml}\right)$ & $M R T_{\mathrm{CLZ}}(\min )$ \\
\hline \multirow[t]{2}{*}{ Blood } & $\mathrm{CLZ}$ micro & $8.0 \pm 2.6$ & $237.5 \pm 21.9$ & $29.6 \pm 1.9$ \\
\hline & $C L Z_{\text {nano }}$ & $11.2 \pm 3.4$ & $335.3 \pm 30.8^{*}$ & $30.0 \pm 2.2$ \\
\hline \multirow[t]{2}{*}{ Cornea } & $\mathrm{CLZ}_{\text {micro }}$ & $80.8 \pm 5.6$ & $1582.5 \pm 105.7$ & $19.5 \pm 1.1$ \\
\hline & $C L Z_{\text {nano }}$ & $165.4 \pm 10.7^{\star}$ & $3397.5 \pm 195.8^{*}$ & $20.5 \pm 1.5$ \\
\hline \multirow[t]{2}{*}{ Lens } & $C L Z_{\text {micro }}$ & $10.4 \pm 1.1$ & $264.3 \pm 11.9$ & $25.3 \pm 1.1$ \\
\hline & $C L Z_{\text {nano }}$ & $18.8 \pm 1.6^{*}$ & $446.1 \pm 16.4^{*}$ & $23.7 \pm 0.9$ \\
\hline \multirow[t]{2}{*}{ Vitreous body } & $\mathrm{CLZ}$ micro & $4.3 \pm 0.1$ & $103.8 \pm 5.4$ & $23.9 \pm 1.2$ \\
\hline & $C L Z_{\text {nano }}$ & $46.0 \pm 2.9^{*}$ & $1088.1 \pm 67.7^{*}$ & $23.6 \pm 1.0$ \\
\hline \multirow[t]{2}{*}{ Sclera and Choroid } & $\mathrm{CLZ}_{\text {micro }}$ & $1284.4 \pm 97.1$ & $23625.6 \pm 896.8$ & $18.4 \pm 0.7$ \\
\hline & $\mathrm{CLZ}_{\text {nano }}$ & $6758.1 \pm 592.7^{*}$ & $141975.0 \pm 4517.7^{*}$ & $20.9 \pm 1.1$ \\
\hline \multirow[t]{2}{*}{ Retina } & $\mathrm{CLZ}_{\text {micro }}$ & $16.4 \pm 0.7$ & $418.5 \pm 9.3$ & $25.6 \pm 1.3$ \\
\hline & $C L Z_{\text {nano }}$ & $149.2 \pm 10.8^{\star}$ & $3831.8 \pm 182.5^{\star}$ & $26.1 \pm 1.0$ \\
\hline \multirow[t]{2}{*}{ Anterior part } & $\mathrm{CLZ}$ micro & $90.2 \pm 9.3$ & $2571.0 \pm 149.3$ & $26.7 \pm 1.0$ \\
\hline & $C L Z_{\text {nano }}$ & $4018.2 \pm 294.5^{*}$ & $101025.8 \pm 3927.1^{*}$ & $25.1 \pm 1.1$ \\
\hline \multirow[t]{2}{*}{ Posterior part } & $\mathrm{CLZ}$ micro & $68.1 \pm 3.5$ & $2130.7 \pm 174.7$ & $31.3 \pm 1.3$ \\
\hline & $C L Z_{\text {nano }}$ & $1090.0 \pm 70.2^{*}$ & $31650.1 \pm 1298.2^{*}$ & $29.0 \pm 1.4$ \\
\hline
\end{tabular}

Parameters were calculated according to Eqs. 1-3 (see Materials and methods). CLZ ${ }_{\text {micro }}, C L Z_{\text {micro }}$-instilled rats; $C L Z_{\text {nano }}, C L Z_{\text {nano }}$-instilled rats. The data are presented as means \pm S.E. of 6 independent rats. ${ }^{*} P<0.05$, vs. $C L Z_{\text {micro }}$ for each category.

Table 3: Pharmacokinetic parameters for CLZ concentrations after the instillation of $C L Z_{\text {micro }}$ or $C L Z_{\text {nano }}$ in blood and cornea, lens, vitreous body,sclera, choroid,retina, anterior andposterior part of right eye

\begin{tabular}{|c|c|c|c|}
\hline & $A U C_{\triangle R V C}(\% \cdot \min )$ & $A U M C_{\triangle R V C}\left(\% \cdot \mathrm{min}^{2}\right)$ & $M R T_{\triangle R V C}(\min )$ \\
\hline Vehicle & $181.3 \pm 7.9$ & $7623.0 \pm 321.5$ & $42.0 \pm 0.8$ \\
\hline $\mathrm{CLZ}_{\text {micro }}$ & $904.1 \pm 31.3^{* 1}$ & $61593.7 \pm 2286.4^{* 1}$ & $68.1 \pm 1.1^{* 1}$ \\
\hline $\mathrm{CLZ}_{\text {nano }}$ & $3909.4 \pm 117.5^{* 1,2}$ & $423018.2 \pm 14105.3^{* 1,2}$ & $108.2 \pm 1.7^{\star 1,2}$ \\
\hline
\end{tabular}

Retinal vasoconstriction in the right eye was caused by intravitreal injection of ET-1. Parameters were calculated according to Eqs. 4-7 (see Materials and methods) Vehicle, vehicle-instilled rats; $C L Z_{\text {micro }}, C L Z_{\text {micro }}$-instilled rats; $C L Z{ }_{\text {nano }}, C L Z_{\text {nano }}$-instilled rats. The data are presented as means $\pm S$.E. of 6 independent rats. ${ }^{*} P<0.05$, vs. vehicle for each category. ${ }^{2} P<0.05$, vs. $C L Z_{\text {micro }}$ for each category.

Table 4: Pharmacokinetic parameters for thesuppression of retinal vasoconstriction by $C L Z_{\text {nano }}$ in rats injected intra vitreally with $E T-1$

intravitreal injection of ET-1, and the RVC in ET-1-injected rats was $49.6 \%$ that of non-treated rats (normal rats) at $30 \mathrm{~min}$ after intravitreal injection. The retinal vasoconstriction in ET-1-injected rats recovered by $48 \mathrm{~h}$ after intravitreal injection. Although, retinal vasoconstriction was suppressed by the instillation of CLZ ${ }_{\text {micro }}$, the efficiency was low, with recovery by $48 \mathrm{~h}$ after intravitreal injection. On the other hand, the $A U C_{\triangle \mathrm{RVC}}$ in rats instilled with $\mathrm{CLZ}_{\text {nano }}$ was significantly higher, and the RVC values in rats instilled with CLZ ${ }_{\text {nano }}$ were similar to those of normal rats $3 \mathrm{~h}$ after intravitreal injection. In addition, no suppression of retinal vasoconstriction was observed in the left eye (non-instillation) of ET-1-injected rats $\left(A U C_{\triangle \mathrm{RVC}} 169.7 \pm 20.5 \% \bullet\right.$ min, mean \pm S.E., $\left.\mathrm{n}=6\right)$.

\section{Discussion}

We designed new ophthalmic formulations containing CLZ solid nanoparticles using the bead mill method [22-24], and investigated the possibility of using these formulations as noninvasive delivery systems targeting the posterior segment of the eye. In addition, we also demonstrated the preventive effect of these ophthalmic formulations containing CLZ nanoparticles on retinal vasoconstriction.

In the design of ophthalmic formulations containing CLZ nanoparticles, the selection of additives is important. BAC is known to have a strong preservative effect, and its surface-active effects increase the corneal penetration of the main component. Therefore, BAC has been seen as an effective preservative and to be indispensable in the preparation of eye drops. However, BAC has been shown to be highly toxic both in vitro and in vivo due to a stimulatory effect on epithelial cell death [30-32]. Clinically, these iatrogenic effects are found most frequently for eye drops used to treat long-term pathologies and inflammation. The side effects of BAC seem to be both dose- and timedependent, increasing with larger amounts used for longer periods. On the other hand, we previously reported that the addition of D-mannitol prevents the corneal stimulation caused by BAC [33]. Moreover, Mori et al. [34] reported that adsorption to the surface of cyclodextrin decreases the cohesion of nanoparticulate solids, and we previously reported that the addition of $\mathrm{HP} \beta \mathrm{CD}$ is suitable for the preparation of nanoparticles using mill methods [22-24,35]. Jansen et al. [36] have reported no observable irritation of the eye membrane by solutions containing HP $\beta C D$ at levels less than $12.5 \%$. Taken together, in this study we attempted to prepare a CLZ dispersion containing BAC, mannitol and 5\% HPßCD using the bead mill method. However, the CLZ became meringue-like when subjected to the bead mill method when CLZ microparticles containing BAC, mannitol and HP $\beta C D$ (Milled-CLZ $\mathrm{MC}_{-(-)}$, Figure $2 \mathrm{~F}$ ) were used. Therefore, a new innovation for the preparation ofCLZdispersionswas required.

MC, a derivative of cellulose, is a water-soluble substance with a high degree of purity, uniformity and transparency. The MC is highly biocompatible [37-39] and is used in the preparation of ophthalmic 
Citation: Nagai N, Yoshioka C, Tanabe W, Tanino T, Ito Y, et al (2015) Effects of Ophthalmic Formulations Containing Cilostazol Nanoparticles on Retinal Vasoconstriction in RatsInjected with Endothelin-1. Pharm Anal Acta 6: 354. doi:10.4172/2153-2435.1000351
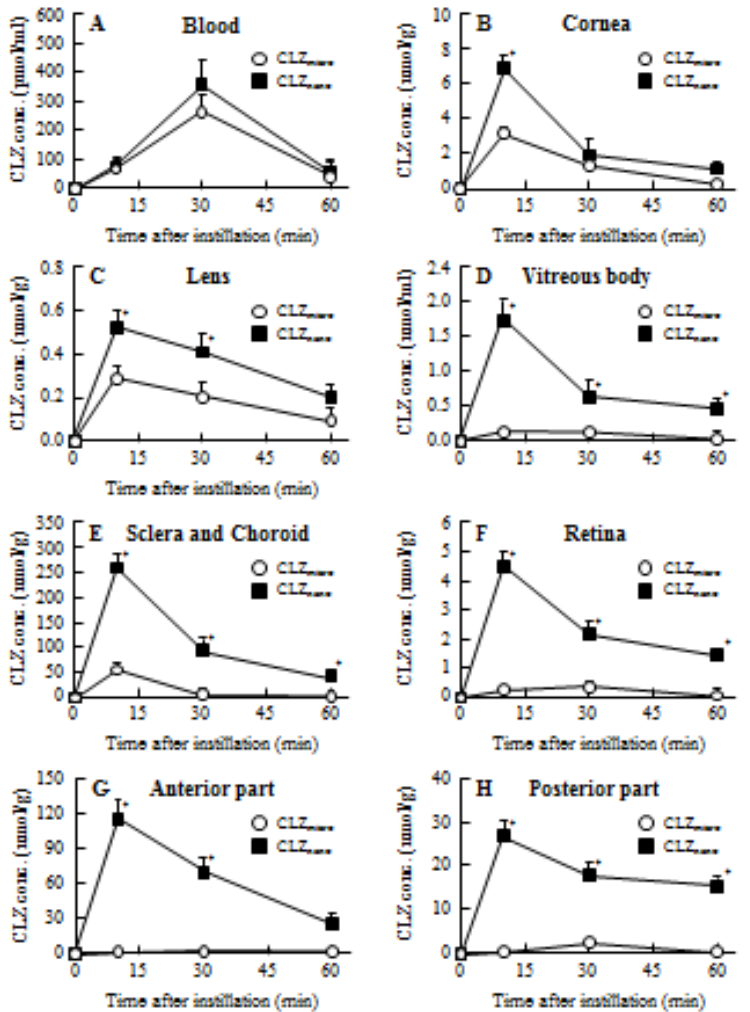

Figure 5: Changes in CLZ concentration in the blood (A), cornea (B), lens $(C)$, vitreous body $(D)$, sclera with choroid $(E)$, retina $(F)$, anterior $(G)$ and posterior part $(\mathrm{H})$ of rats instilled with dispersions containing CLZ micro- or nanoparticles. Rat eyes were instilled with $30 \mu$ of dispersions containing CLZ microparticles $\left(C L Z_{\text {micro }}\right)$ or nanoparticles $\left(C L Z_{\text {nano }}\right)$. The data are presented as the means \pm S.E. of 6 independent experiments. ${ }^{*} P<0.05$, vs. $C L Z_{\text {micro }}$.
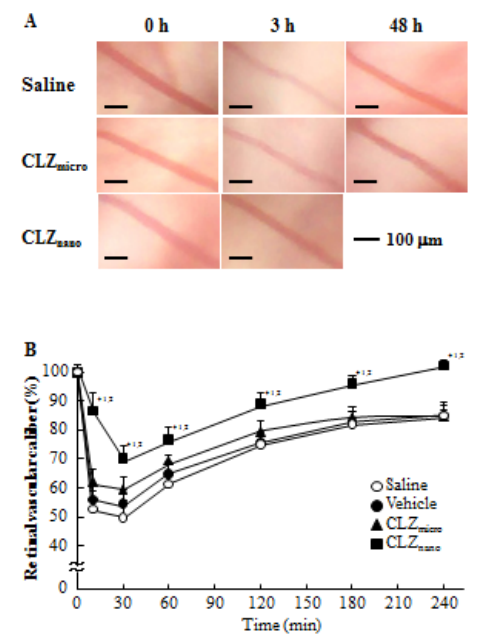

Figure 6: Effect of dispersions containing CLZ nanoparticles on retinal vascular caliber in rats injected with ET-1. Rat eyes were instilled with $30 \mu$ of dispersions containing $\mathrm{CLZ}$ microparticles $\left(\mathrm{CLZ} \mathrm{m}_{\text {moro }}\right)$ or nanoparticles $\left(\mathrm{CLZ} \mathrm{n}_{\mathrm{n}}\right)$, and retinal vasoconstriction of the right eye was caused by the intravitreal injection of ET-1. RVC (\%) was monitored using a Digital Microscope, and calculated according to Eq. 4 (see Materials and methods). The data are presented as the means \pm S.E. of 6 independent experiments. ${ }^{*} P<0.05$, vs. saline. ${ }^{*} P<0.05$, vs. $\mathrm{CLZ}$ micro formulations. Mueller and Deardorff et al. [40] stated that MC does not cause eye irritation or damage, and they used $1 \% \mathrm{MC}$ in the development of ophthalmic formulations. The gel strength depends on the degree of substitution and the molecular weight [41,42]. In addition, our previously reports showed that the addition of MC enhanced the crushing efficiency of bead mill method [22,24]. The CLZ particle size was decreased using a combination of $\mathrm{MC}$ and the bead mill method, and the CLZ particle size reached the nano order by the bead mill method using CLZ microparticles containing BAC, mannitol, $\mathrm{HP} \beta \mathrm{CD}$ and $\mathrm{MC}\left(\mathrm{CLZ}_{\text {nano }}\right.$, Figure $2 \mathrm{E}$ and $\left.\mathrm{G}\right)$. The size of a particle influences its functionality in terms of uptake, residence time in circulation, adherence, degradation, as well as clearance [43-47]. The fate of particles inside the body has been reported as follows: $\geqq 2 \mu \mathrm{m}$, trapped inside liver cells; $\geqq 300-400 \mathrm{~nm}$, captured by macrophages and excreted; $\geqq 200 \mathrm{~nm}$, filtered in the spleen; $\leqq 100 \mathrm{~nm}$, escape from blood vessels through the endothelial lining. Thus, size governs the movement of nanoparticles inside tissues. In the ophthalmic field, nanoparticles in sizes ranging from 10 to $1000 \mathrm{~nm}$ allow for improved topical passage of large, water insoluble molecules through the barriers of the ocular system[48]. In this study, the particles size of CLZ $Z_{\text {nano }}$ is 61 $\mathrm{nm}$, and it is expected that $\mathrm{CLZ}_{\text {nano }}$ may provide an alternative strategy for increasing ocular drug penetration. In addition, the stability of dispersions containing CLZnanoparticlesis increased by the addition of $5 \% \mathrm{HP} \beta \mathrm{CD}\left(\mathrm{CLZ}_{\text {nano }}\right.$, Fig. 3). Furthermore, we examined whether the preservative effect and stability of CLZ in the CLZ ${ }_{\text {nano }}$ formulation are changed, or not. Although, no antimicrobial activity of CLZ itself was observed, the CLZ $Z_{\text {nano }}$ preparation showed high antimicrobial activity approximately equal to that of a $0.001 \%$ BAC solution (Fig. 4), andno degradation or reduction in the amount of CLZ in CLZ formulations with or without BAC was detected by HPLC methods.

Next, we evaluated CLZ concentrations in blood and cornea, lens, vitreous body, sclera, choroid, retina, anterior and posterior part of the right eye of rats after the instillation of CLZ $Z_{\text {nano }}$ The determination of the concentration in ophthalmic formulation is important. We previously reported that the instillation of $0.05 \%$ CLZ ophthalmic solution decrease the enhanced Intraocular Pressure (IOP), and was useful for the therapeutic treatment of the glaucoma [35]. However, it is difficult to deliver the drug to retina by the ophthalmic formulation containing low drug concentration. Therefore, we attempted to prepare the CLZ ophthalmic formulation containing high drug concentration, and successful to prepare the $1 \%$ CLZ ophthalmic formulation. Taken together, we used the ophthalmic formulations containing 1\% CLZ in this study. In many studies in the ophthalmic field, labeling with a fluorescence reagent, such as coumarin- 6 , has been used to investigate drug behavior [49]; however, this technique was not applied to the nanoparticles prepared by a bead mill method because the particle size would be changed by labeling. Therefore, we measured changes in the CLZ concentration in ocular tissues.In general, topically administered drugs are absorbed either through the corneal route (cornea $\rightarrow$ aqueous humor $\rightarrow$ intraocular tissues) or non-corneal route (conjunctiva $\rightarrow$ sclera $\rightarrow$ choroid/retinalpigment epithelium)[50]. In addition, drugs absorbed into the conjunctiva can enter the aqueous humor as well as the sclera, showing good access to the trabecular meshwork, iris root and pars plana [51]. In the CLZ-instilled right eye field, such as the cornea, lens, vitreous body, sclera, choroid, retina, anterior and posterior part (Fig. 5B-H), the CLZ concentrations in rats instilled with $\mathrm{CLZ}_{\text {nano }}$ were significantly higher than in rats instilled with CLZ ${ }_{\text {micro }}$ in this study. In contrast to the results for $A U C_{\mathrm{CLZ}}$ and $M R T_{\mathrm{CLZ}}$ in the right eye field of rats instilled with $\mathrm{CLZ}_{\text {nano }}$, CLZ concentrations in the left retina, which received no drug instillation,were undetectable. In 
Citation: Nagai N, Yoshioka C, Tanabe W, Tanino T, Ito Y, et al (2015) Effects of Ophthalmic Formulations Containing Cilostazol Nanoparticles on Retinal Vasoconstriction in RatsInjected with Endothelin-1. Pharm Anal Acta 6: 354. doi:10.4172/2153-2435.1000351

addition, no significant difference in plasma CLZ concentration was observed.Taken together, although further investigation is required, the delivery of $\mathrm{CLZ}_{\text {nano }}$ to the posterior segment of the eye might occur viaboth corneal and non-corneal pathways.

In order to study accurately the effects of ophthalmic formulations containing CLZ nanoparticles on the retina and posterior segment, the selection of the experimental model is very important. ET-1, which is thought to be a highly relevant factor for ocular blood flow, is known to be a very potent and long-lasting vasoconstrictor peptide originating in endothelial cells [52]. In the retina, the ET-1 is a potent vasoactive peptide that causes vasoconstriction of retinal vessels. ET-1 and its receptors have been found in ocular tissues where it appears to have a regulatory function $[53,54]$. ET- 1 is found in both the aqueous and vitreous humors and its concentration is elevated in glaucoma patients [55-58] and in animal models of glaucoma [59-61]. ET-1 is an important contributing factor in retinal injuryof retina and optic neuropathy. Therefore, we evaluated the effects of $\mathrm{CLZ}_{\text {nano }}$ using ET-1-induced retinal injury in rats. Retinal vasoconstriction was observed following the intravitreal injection of ET-1, and this retinal vasoconstriction was suppressed by the instillation of CLZ $Z_{\text {nano }}$. In addition, no suppression of retinal vasoconstriction was observed in the left eye (non-instillation) of ET-1-injected rats. These results suggest that the instillation of $\mathrm{CLZ}_{\text {nano }}$ can prevent retinal vasoconstriction viaan ocular route.

Further studies are needed to elucidate the usefulness and the route of CLZ after the instillation of dispersions containing CLZ nanoparticles. Therefore, we are now investigating the route of CLZ after the instillation of dispersions containing CLZ nanoparticles using rabbits. In addition, we are demonstrating the effect by the ophthalmic formulation containing the different CLZ concentration.

In the present study, we attempted to establish a new method for preparing drug solid nanoparticles, and succeeded in preparing a high quality dispersion containing CLZ nanoparticles. The state of the dispersions containing CLZ nanoparticles does not affect the antimicrobial activity of BAC against E. coli, and the instillation of the ophthalmic dispersions containing CLZ nanoparticles suppresses retinal vasoconstriction in ET-1-injected rats. It is possible that dispersions containing CLZ nanoparticles provide new possibilities for the effective delivery of therapeutic agents to intraocular tissues such as the retina using non-invasive delivery methods, and that an ocular drug delivery system using drug nanoparticles may expand their usage for therapy in the ophthalmologic field.

\section{References}

1. Fattal E, Bochot A (2006) Ocular delivery of nucleic acids: antisense oligonucleotides, aptamers and siRNA. Adv Drug Deliv Rev 58: 1203-1223.

2. Colucciello $M$ (2008) Intravitrealbevacizumab and triamcinolone acetonide combination therapy for exudative neovascular age-related macular degeneration: short-term optical coherence tomography results. J Ocul Pharmacol Ther 24: 15-24.

3. Yasukawa T, Kimura H, Tabata Y, Ogura Y (2001) Biodegradable scleral plugs for vitreoretinal drug delivery. Adv Drug Deliv Rev 52: 25-36.

4. Yasukawa T, Ogura Y, Tabata Y, Kimura H, Wiedemann P, et al. (2004) Drug delivery systems for vitreoretinal diseases. Prog Retin Eye Res 23: 253-281.

5. Ammar HO, Salama HA, Ghorab M, Mahmoud AA (2009) Nanoemulsion as a potential ophthalmic delivery system for dorzolamide hydrochloride. AAPS Pharm SciTech 10: 808-819.

6. El-Kamel AH1 (2002) In vitro and in vivo evaluation of Pluronic F127-based ocular delivery system for timolol maleate. Int J Pharm 241: 47-55.

7. Sultana Y, Aqil M, Ali A (2006) lon-activated, Gelrite-based in situ ophthalmic gels of pefloxacinmesylate: comparison with conventional eye drops. Drug Deliv 13: 215-219.
8. Diebold Y, Jarrín M, Sáez V, Carvalho EL, Orea M, et al. (2007) Ocular drug delivery by liposome-chitosan nanoparticle complexes (LCS-NP). Biomaterials 28: 1553-1564.

9. Asasutjarit R, Thanasanchokpibull S, Fuongfuchat A, Veeranondha S (2011) Optimization and evaluation of thermoresponsivediclofenac sodium ophthalmic in situ gels. Int J Pharm 411: 128-135.

10. Gupta H, Aqil M, Khar RK, Ali A, Bhatnagar A, et al. (2011) Biodegradable levofloxacin nanoparticles for sustained ocular drug delivery. J Drug Target 19: $409-417$

11. Casolaro M, Casolaro I, Lamponi S (2012) Stimuli-responsive hydrogels for controlled pilocarpine ocular delivery. Eur J Pharm Biopharm 80: 553-561.

12. Li X, Zhang Z, Li J, Sun S, Weng Y, et al. (2012) Diclofenac/biodegradable polymer micelles for ocular applications. Nanoscale 4: 4667-4673.

13. Davies NM, Farr SJ, Hadgraft J, Kellaway IW (1991) Evaluation of mucoadhesive polymers in ocular drug delivery. I. Viscous solutions. Pharm Res 8: 1039-1043.

14. Rafie F, Javadzadeh $Y$, Javadzadeh AR, Ghavidel LA, Jafari B, et al. (2010) In vivo evaluation of novel nanoparticles containing dexamethasone for ocular drug delivery on rabbit eye. Curr Eye Res 35: 1081-1089.

15. Zhou HY, Hao JL, Wang S, Zheng Y, Zhang WS (2013) Nanoparticles in the ocular drug delivery. Int J Ophthalmol 6: 390-396.

16. Rahul M, Mohita U, Sanat M (2014)Design Considerations for Chemotherapeutic Drug Nanocarriers. Pharm Anal Acta 5: 279

17. Tomoda K, Terashima H, Suzuki K, Inagi T, Terada H, et al. (2011) Enhanced transdermal delivery of indomethacin-loaded PLGA nanoparticles by iontophoresis. Colloids Surf B Biointerfaces 88: 706-710.

18. Tomoda K, Watanabe A, Suzuki K, Inagi T, Terada H, et al. (2012) Enhanced transdermal permeability of estradiol using combination of PLGA nanoparticles system and iontophoresis. Colloids Surf B Biointerfaces 97: 84-89.

19. Tomoda K, Terashima H, Suzuki K, Inagi T, Terada H, et al. (2012) Enhanced transdermal delivery of indomethacin using combination of PLGA nanoparticles and iontophoresis in vivo. Colloids Surf B Biointerfaces 92: 50-54.

20. Nagai N, Ito $Y(2014)$ Therapeutic effects of gel ointments containing tranilast nanoparticles on paw edema in adjuvant-induced arthritis rats. Biol Pharm Bull 37: 96-104.

21. Nagai N, Ito $Y$ (2014) Effect of solid nanoparticle of indomethacin on therapy for rheumatoid arthritis in adjuvant-induced arthritis rat. Biol Pharm Bull 37: 1109-1118.

22. Nagai N, Ito $\mathrm{Y}$, Okamoto N3, Shimomura Y3 (2014) A nanoparticle formulation reduces the corneal toxicity of indomethacin eye drops and enhances its corneal permeability. Toxicology 319: 53-62.

23. Nagai $N$, Ono $H$, Hashino $M$, Ito $Y$, Okamoto $N$, et al. (2014) Improved corneal toxicity and permeability of tranilast by the preparation of ophthalmic formulations containing its nanoparticles. J Oleo Sci 63: 177-186.

24. Nagai N, Yoshioka C, Mano Y, Tnabe W, Ito Y, et al. (2015) A nanoparticle formulation of disulfiram prolongs corneal residence time of the drug and reduces intraocular pressure. Exp Eye Res 132: 115-123.

25. Chapman TM, Goa KL (2003) Cilostazol: a review of its use in intermittent claudication. Am J Cardiovasc Drugs 3: 117-138.

26. Kambayashi J, Liu Y, Sun B, Shakur Y, Yoshitake M, et al. (2003) Cilostazol as a unique antithrombotic agent. Curr Pharm Des 9: 2289-2302.

27. Jung KI, Kim JH, Park HY, Park CK (2013) Neuroprotective effects of cilostazo on retinal ganglion cell damage in diabetic rats. J PharmacolExpTher 345 457-463.

28. Hotta H, Ito H, Kagitani F, Sato A (1998) Cilostazol, a selective cAMPphosphodiesterase inhibitor, dilates retinal arterioles and increases retinal and choroidal blood flow in rats. Eur J Pharmacol 344: 49-52.

29. YakujiNippo Ltd (2011) Japanese Pharmacopoeia. (16 ${ }^{\text {th }}$ Edition), Maruzen Co Ltd, Tokyo.

30. Rolando M, Brezzo G, Giordano P, Campagna P, Burlando S, et al. (1991) The Lacrimal System, by Van Bijsterweld OP, Lemp MA, Spinelli D, Kagler\&Ghedin Amsterdam, pp. 89-91. 
Citation: Nagai N, Yoshioka C, Tanabe W, Tanino T, Ito Y, et al (2015) Effects of Ophthalmic Formulations Containing Cilostazol Nanoparticles on Retinal Vasoconstriction in RatsInjected with Endothelin-1. Pharm Anal Acta 6: 354. doi:10.4172/2153-2435.1000351

31. Debbasch C, Brignole F, Pisella PJ, Warnet JM, Rat P, et al. (2001) Quaternary ammoniums and other preservatives' contribution in oxidative stress and apoptosis on Chang conjunctival cells. Invest Ophthalmol Vis Sci 42: 642-652.

32. Debbasch C, Pisella PJ, De Saint Jean M, Rat P, Warnet JM, et al. (2001) Mitochondrial activity and glutathione injury in apoptosis induced by unpreserved and preserved beta-blockers on Chang conjunctival cells. Invest Ophthalmol Vis Sci 42: 2525-2533.

33. Nagai N, Murao T, Oe K, Ito $\mathrm{Y}$, Okamoto $\mathrm{N}$, et al. (2011) [In vitro evaluation for corneal damages by anti-glaucoma combination eye drops using human corneal epithelial cell (HCE-T)]. Yakugaku Zasshi 131: 985-991.

34. Mori K, Yoshioka N, Kondo Y, Takeuchi T, Yamashita H (2009) Catalytically Active, Magnetically Separable, and Water-soluble FePt Nanoparticles Modified with Cyclodextrin for Aqueous Hydrogenation Reactions. Green Chem 11: 1337-1342

35. Okamoto N, Ito Y, Nagai N, Murao T, Takiguchi Y, et al. (2010) Preparation of ophthalmic formulations containing cilostazol as an anti-glaucoma agent and improvement in its permeability through the rabbit cornea. J Oleo Sci 59:423430.

36. Jansen T, Xhonneux B, Mesens J, Borgers M (1990) Beta-cyclodextrins as vehicles in eye-drop formulations: an evaluation of their effects on rabbit corneal epithelium. Lens Eye Toxic Res 7: 459-468.

37. Wells MR, Kraus K, Batter DK, Blunt DG, Weremowitz J, et al. (1997) Ge matrix vehicles for growth factor application in nerve gap injuries repaired with tubes: a comparison of biomatrix, collagen, and methylcellulose. ExpNeuro 146: 395-402.

38. Tate MC, Shear DA, Hoffman SW, Stein DG, LaPlaca MC (2001) Biocompatibility of methylcellulose-based constructs designed for intracerebral gelation following experimental traumatic brain injury. Biomaterials 22: 1113-

39. Gupta D, Tator CH, Shoichet MS (2006) Fast-gelling injectable blend of hyaluronan and methylcellulose for intrathecal, localized delivery to the injured spinal cord. Biomaterials 27: 2370-2379.

40. MUELLER WH, DEARDORFF DL (1956) Ophthalmic vehicles: the effect of methylcellulose on the penetration of homatropinehydrobromide through the cornea. J Am Pharm Assoc Am Pharm Assoc (Baltim) 45: 334-341.

41. Kundu PP, Kundu M (2001) Effect of Salts and Surfactant and Their Doses on the Gelation of Extremely Dilute Solutions of Methyl Cellulose. Polymer 42 2015-2020.

42. Sanz T, Fernandez MA, Salvador A, Munoz J, Fiszman SM (2005) Thermogelation properties of methylcellulose (MC) and their effect on a batter formula. Food Hydrocolloids 19: 141-147.

43. Chouly C, Pouliquen D, Lucet I, Jeune JJ, Jallet P (1996) Development of superparamagnetic nanoparticles for MRI: effect of particle size, charge and surface nature on biodistribution. J Microencapsul 13: 245-255.

44. Begley DJ1 (2004) Delivery of therapeutic agents to the central nervous system: the problems and the possibilities. PharmacolTher 104: 29-45.

45. Bareford LM, Swaan PW (2007) Endocytic mechanisms for targeted drug delivery. Adv Drug Deliv Rev 59: 748-758.

46. Dobrovolskaia MA, Aggarwal P, Hall JB, McNeil SE (2008) Preclinical studies to understand nanoparticle interaction with the immune system and its potential effects on nanoparticle biodistribution. Mol Pharm 5: 487-495.

47. Toy R, Peiris PM, Ghaghada KB, Karathanasis E (2014) Shaping cance nanomedicine: the effect of particle shape on the in vivo journey of nanoparticles. Nanomedicine (Lond) 9: 121-134.
48. Diebold Y, Calonge M (2010) Applications of nanoparticles in ophthalmology ProgRetin Eye Res 29: 596-609.

49. Hironaka K, Inokuchi Y, Tozuka Y, Shimazawa M, Hara H, et al. (2009) Design and evaluation of a liposomal delivery system targeting the posterior segment of the eye. J Control Release 136: 247-253.

50. Liu S, Jones L, Gu FX (2012) Nanomaterials for ocular drug delivery. MacromolBiosci 12: 608-620.

51. Koevary SB (2003) Pharmacokinetics of topical ocular drug delivery: potentia uses for the treatment of diseases of the posterior segment and beyond. Cur Drug Metab 4: 213-222.

52. Yanagisawa M, Kurihara H, Kimura S, Tomobe $Y$, Kobayashi M, et al. (1988) A novel potent vasoconstrictor peptide produced by vascular endothelial cells. Nature 332: 411-415.

53. Ripodas A, de Juan JA, Roldán-Pallarés M, Bernal R, Moya J, et al. (2001) Localisation of endothelin-1 mRNA expression and immunoreactivity in the retina and optic nerve from human and porcine eye. Evidence for endothelin-1 expression in astrocytes. Brain Res 912: 137-143.

54. Fernández-Durango R, Rollín R, Mediero A, Roldán-Pallares M, GarcíaFeijo $\mathrm{J}$, et al. (2003) Localization of endothelin-1 mRNA expression and immunoreactivity in the anterior segment of human eye: expression of ETA and ETB receptors. Mol Vis 9: 103-109.

55. Sugiyama T, Moriya S, Oku H, Azuma I (1995) Association of endothelin-1 with normal tension glaucoma: clinical and fundamental studies. Surv Ophthalmol 39 Suppl 1: S49-56.

56. Cellini M, Possati GL, Profazio V, Sbrocca M, Caramazza N, et al. (1997) Color Doppler imaging and plasma levels of endothelin-1 in low-tension glaucoma. ActaOphthalmolScandSuppl : 11-13.

57. Tezel G, Kass MA, Kolker AE, Becker B, Wax MB (1997) Plasma and aqueous humor endothelin levels in primary open-angle glaucoma. J Glaucoma 6: 8389.

58. Holló G, Lakatos P, Farkas K (1998) Cold pressor test and plasma endothelin-1 concentration in primary open-angle and capsular glaucoma. J Glaucoma 7 105-110.

59. Källberg ME, Brooks DE, Garcia-Sanchez GA, Komàromy AM, Szabo NJ, et al. (2002) Endothelin 1 levels in the aqueous humor of dogs with glaucoma. J Glaucoma 11: 105-109.

60. Thanos S, Naskar R (2004) Correlation between retinal ganglion cell death and chronically developing inherited glaucoma in a new rat mutant. Exp Eye Res 79: 119-129.

61. Nagata A, Omachi K, Higashide T, Shirae S, Shimazaki A, et al. (2014) OCT evaluation of neuroprotective effects of tafluprost on retinal injury after intravitreal injection of endothelin-1 in the rat eye. Invest Ophthalmol Vis Sci 55: 1040-1047. 